\title{
Dr. Dahir Ramos de Andrade
}

Os Editores e Colaboradores dos ARQUIVOS de GASTROENTEROLOGIA, pesarosos, comunicam o falecimento do Dr. Dahir Ramos de Andrade, ocorrido em abril passado.

Dr. Dahir graduou-se em 1959 pela Faculdade de Medicina da Universidade de São Paulo, com Doutoramento pela mesma Universidade, em 1966, onde exercia suas atividades didáticas junto ao Departamento de Doenças Infecciosas e Parasitárias.

Exerceu suas atividades profissionais no IGESP Instituto de Gastroenterologia de São Paulo - onde, ao lado do Dr. Luis Caetano da Silva e do Prof. José Fernandes Pontes, foram os precursores da Hepatologia como especialidade médica.
Participou academicamente das atividades do IBEPEGE - Instituto de Estudos e Pesquisas de Gastroenterologia, proferindo aulas e seminários no Curso de Formação de Especialistas e no de Mestrado, além da organização do prestigiado Curso Anual de Hepatologia, com renomados especialistas do Brasil e do exterior.

A participação editorial do Dr. Dahir junto aos ARQUIVOS de GASTROENTEROLOGIA foi inestimável, na elaboração e revisão de trabalhos científicos, colaborando para que a revista conseguisse atingir o seu elevado reconhecimento dentro da comunidade médica e acadêmica.

Mounib TACLA*

* Editor Científico dos ARQUIVOS de GASTROENTEROLOGIA 